\title{
Spermatozoa of the Atlantic bottlenosed dolphin, Tursiops truncatus
}

\author{
A. D. Fleming, R. Yanagimachi and H. Yanagimachi \\ Department of Anatomy and Reproductive Biology, University of Hawaii School of Medicine, \\ Honolulu, Hawaii 96822, U.S.A.
}

\begin{abstract}
Summary. Semen from a male dolphin in captivity was collected by electroejaculation and frozen to $-176^{\circ} \mathrm{C}$. Sperm motility was excellent after thawing 10 days later. Electron microscopy showed 14-16 parallel ridges in the post-acrosomal region and two types of mitochondria in the mid-piece. The spermatozoa were capable of fusing with zona-free hamster eggs only after preincubation for $2 \mathrm{~h}$, suggesting the need for sperm capacitation and acrosome reaction before fertilization in this species.
\end{abstract}

\section{Introduction}

Several studies dealing with gonadal histology and embryogenesis of dolphins have been reported (Fisher \& Harrison, 1970; Harrison \& Brownell, 1971; Harrison \& Ridgway, 1971; Harrison, Brownell \& Boice, 1972). The gonads described were often immature, seasonally inactive or inactive possibly as a consequence of stress in captivity. Epididymal spermatozoa have been reported as present in cetaceans (Fisher \& Harrison, 1970; Harrison \& Brownell, 1971; Harrison et al., 1972) but have not been described except for spermatozoa of the sperm whale (Matano, Matsubayashi, Omichi \& Ohtomo, 1976). Seager, Gilmartin, Moore, Platz \& Kirby (1981) have induced electroejaculation of the bottlenosed dolphin and we have studied the morphology of dolphin spermatozoa and their apparent capacitation and acquisition of egg-penetrating ability.

\section{Materials and Methods}

\section{Male and semen characteristics}

A male bottlenosed dolphin (Tursiops truncatus: No. 16, $193 \mathrm{~kg}$ body weight; 14 years old and 12 years in captivity) (Seager et al., 1981) was the semen donor for the present study. The electroejaculation procedures and the semen characteristics have been described previously (Seager et al., 1981). The volume of a single ejaculate obtained was $18 \mathrm{ml}$. The incidence of abnormal forms of spermatozoa in the ejaculate was $<10 \%$. The semen diluent $(20 \%(\mathrm{v} / \mathrm{v}) \mathrm{egg}$ yolk, $11 \%(\mathrm{w} / \mathrm{v})$ lactose and $4 \%(\mathrm{v} / \mathrm{v})$ glycerol) and the 'pellet' method for freezing were those reported by Seager, Platz \& Fletcher (1975) for successful freezing of canine spermatozoa. Diluted semen $(1: 3 \mathrm{v} / \mathrm{v})$ was dropped from a Pasteur pipette onto solid $\mathrm{CO}_{2}$ to form individual frozen pellets. The frozen pellets were then transferred to liquid nitrogen $\left(-176^{\circ} \mathrm{C}\right)$ and stored for up to 10 days. The percentage of actively motile spermatozoa was $85 \%$ before freezing and $80 \%$ after thawing on any day of the 10 -day storage period. 


\section{Examination of sperm survival in various media}

A frozen semen pellet was removed from liquid nitrogen and immersed immediately in $2 \mathrm{ml}$ $0.9 \%(\mathrm{w} / \mathrm{v}) \mathrm{NaCl}$ at $37^{\circ} \mathrm{C}$. The medium was gently stirred to distribute the thawing sample evenly. After thawing, several drops of the sperm suspension were added to $1.5 \mathrm{ml}$ of a test medium in a plastic Petri dish $(10 \times 30 \mathrm{~mm}$; Falcon Plastics, Oxnard, California) so that the concentration of spermatozoa became approximately $6 \times 10^{6}$ per ml. After covering the surface of the medium with mineral oil (Squibb and Sons, Princeton, New Jersey) to prevent evaporation, the preparation was incubated at $37^{\circ} \mathrm{C}$ under pure air or $5 \% \mathrm{CO}_{2}$ in air. At various intervals the survival and motility characteristics of the spermatozoa were examined with phase-contrast or dark-field optics. The culture media tested were canine capacitation medium (CCM; Mahi \& Yanagimachi, 1978), modified Tyrode's solution (mT; Fleming \& Yanagimachi, 1981) and modified Krebs-Ringer solution (BWW; Biggers, Whitten \& Whittingham, 1971).

\section{In-vitro capacitation of spermatozoa}

Since dolphin eggs were not available for this study, zona-free hamster eggs were used to evaluate the possible need for capacitation of dolphin spermatozoa. The zona-free hamster egg system has been used to assess capacitation and the acrosome reaction of spermatozoa from such diverse species as the guinea-pig (Yanagimachi, 1972, 1978), pig (Imai, Niwa \& Iritani, 1979), and man (Yanagimachi, Yanagimachi \& Rogers, 1976; Fleming, Yanagimachi \& Yanagimachi, 1979; Kanwar, Yanagimachi \& Lopata, 1979). Our preliminary study indicated that dolphin spermatozoa are better capacitated in vitro when first incubated in $\mathrm{Ca}^{2+}$-free medium and then exposed to $\mathrm{Ca}^{2+}$ than when incubated continuously in $\mathrm{Ca}^{2+}$-containing medium. The procedure used was as follows. Unwashed spermatozoa suspended in $0.9 \%(\mathrm{w} / \mathrm{v})$ $\mathrm{NaCl}$ were added to $1.5 \mathrm{ml} \mathrm{Ca}{ }^{2+}$-free test medium to give a concentration of $6 \times 10^{6}$ spermatozoa $/ \mathrm{ml}$, and the medium was covered with mineral oil. After incubation for $2 \mathrm{~h}$ at $37^{\circ} \mathrm{C}$, an equal volume of the same medium but containing $3.4 \mathrm{~mm}-\mathrm{CaCl}_{2}$ was added, thus giving final concentrations of $3 \times 10^{6}$ spermatozoa/ml and $1.7 \mathrm{mM}^{-\mathrm{Ca}^{2+}}$. At $10 \mathrm{~min}$ after the addition of $\mathrm{Ca}^{2+}, 10-20$ zona-free hamster eggs were introduced into the sperm suspension. The preparation was incubated at $37^{\circ} \mathrm{C}$. The method for preparation of zona-free hamster eggs has been described previously (Fleming et al., 1979). Eggs were examined by phase-contrast microscopy for evidence of sperm penetration into their vitelli $2 \mathrm{~h}$ after insemination. An egg was recorded 'penetrated' when at least one swollen sperm head and associated tail were discernible within the vitellus.

Examination of sperm morphology by scanning (SEM) and transmission (TEM) electron microscopy

For SEM, spermatozoa were fixed with $1 \%$ glutaraldehyde in $0.1 \mathrm{M}$-cacodylate buffer $(\mathrm{pH}$ 7.4) for $1 \mathrm{~h}$ at room temperature, and washed with $0.9 \%(\mathrm{w} / \mathrm{v}) \mathrm{NaCl}$ by centrifugation $(500 \mathrm{~g}$ for $5 \mathrm{~min}$ ). The spermatozoa were spread on a $22 \times 22 \mathrm{~mm}$ coverslip and immediately after air drying were dehydrated through an ethanol series. The preparations were stored over a silica desiccant. The spermatozoa were coated with gold-palladium in a SAM Sputterer (Tousimis Corp., Rockville, Maryland) and observed at $10 \mathrm{kV}$ with a Cambridge S4-10 Stereoscan (Cambridge, England). For TEM, spermatozoa were fixed for $1 \mathrm{~h}$ at room temperature in $2.5 \%$ glutaraldehyde in $0.1 \mathrm{M}$-cacodylate buffer ( $\mathrm{pH} 7.4$ ), washed with the buffer and post-fixed for 1 $\mathrm{h}$ with $1 \%$ osmium tetroxide in $0.1 \mathrm{M}$-cacodylate buffer $(\mathrm{pH} 7 \cdot 4)$. After washing three times with $0.05 \mathrm{M}$-maleate buffer ( $\mathrm{pH} \mathrm{5.2)}$ ), the samples were treated with $0.5 \%$ uranyl acetate in the maleate buffer ( $\mathrm{pH}$ 6.0), dehydrated with an ethanol series, and embedded in Epon. Thin sections were stained with uranyl acetate and lead citrate before examination with a Philips EM-300 electron microscope. 


\section{Results}

\section{Morphology of spermatozoa}

Our observations showed that the overall structure of the spermatozoa of this dolphin is not markedly different from that described for other eutherian mammals (Fawcett, 1975), but differences in some components were detected.

The head has an elongated ellipsoid shape in surface view and a bullet shape in lateral view (Pl. 1, Figs 1 and 2). The sperm dimensions were head length, $4.5 \mu \mathrm{m}$; head width, $2.0 \mu \mathrm{m}$; middle piece length, $4.0 \mu \mathrm{m}$; tail length including the middle piece, $60 \mu \mathrm{m}$; total length, about 65 $\mu \mathrm{m}$. The acrosome, which covers the anterior half of the sperm nucleus, is very thin and flat (Pl. 2, Figs 4 and 5) with the exception of the posterior region of the acrosome which is thickened and may represent the equatorial segment of the acrosome (see the sagittal section shown in $\mathrm{Pl}$. 2, Fig. 4). The post-acrosomal region occupies the posterior half of the sperm head and is characterized by 14-16 elevated ridges running parallel to the long axis of the spermatozoon (Pl. 1, Fig. 3; Pl. 3, Fig. 6). Examination of transverse sections of the ridges under high magnification revealed distinct globular structures between the plasma membrane and the nuclear envelope (Pl. 3, Figs 7 and 8). These structures may represent specialized post-acrosomal dense laminae. No unusual structures were observed in the sperm tail, but two possibly distinct types of mitochondria with different affinities for heavy metal stains were noted (Pl. 3, Fig. 9; Pl. 4, Figs 10 and 11).

\section{Survival of spermatozoa in various media}

Spermatozoa thawed and suspended in test media showed very rapid progressive movement. Spermatozoa survived best in Medium CCM followed by Media MT and BWW (Table 1). The use of $5 \% \mathrm{CO}_{2}$ in air as incubation atmosphere appeared to be superior to pure air in maintaining the viability of spermatozoa in Media CCM and $\mathrm{mT}$.

Table 1. Survival of dolphin spermatozoa in three different media $\left(37^{\circ} \mathrm{C}\right)$

\begin{tabular}{llcccc}
\hline & & & \multicolumn{2}{c}{$\begin{array}{c}\text { Visual estimation (mean \%) } \\
\text { of progressively motile } \\
\text { spermatozoa at: }\end{array}$} \\
\cline { 3 - 6 } Medium & $\begin{array}{c}\text { Incubation } \\
\text { atmosphere }\end{array}$ & $\begin{array}{c}\text { No. of } \\
\text { experiments }\end{array}$ & $30 \mathrm{~min}$ & $\mathbf{6 - 8 \mathrm { h }}$ & $\mathbf{2 2 \mathrm { h }}$ \\
\hline $\mathrm{CCM}$ & $5 \% \mathrm{CO}_{2}$ in air & 3 & 80 & 80 & 70 \\
& Pure air & 3 & 70 & 70 & 50 \\
$\mathrm{mT}$ & $5 \% \mathrm{CO}_{2}$ in air & 3 & 80 & 80 & 50 \\
& Pure air & 3 & 70 & 50 & 10 \\
$\mathrm{BWW}$ & $5 \% \mathrm{CO}_{2}$ in air & 2 & 70 & 40 & 0 \\
& Pure air & 2 & 70 & 40 & 0 \\
\hline
\end{tabular}

\section{In-vitro capacitation of spermatozoa}

When frozen spermatozoa were thawed in $0.9 \% \mathrm{NaCl}$ and immediately mixed with zona-free hamster eggs in regular test media, none of the 60 eggs tested was penetrated within $2 \mathrm{~h}$. The results after preincubation for $2 \mathrm{~h}$ are shown in Table 2. All three media supported capacitation of dolphin spermatozoa as judged by their ability to penetrate zona-free hamster eggs (Pl. 4, Figs 12-14). The highest rate of sperm penetration (probably reflecting the best sperm capacitation and acrosome reaction) was obtained with spermatozoa incubated in Medium CCM under pure air. About $5 \%$ of the motile spermatozoa exhibited a vigorous 'activated' type of movement characterized by high-amplitude whiplash beating of their flagella. 
Table 2. Capacitation of dolphin spermatozoa as demonstrated by their ability to fuse with zona-free hamster eggs

\begin{tabular}{clccc}
\hline Medium & $\begin{array}{c}\text { Incubation } \\
\text { atmosphere }\end{array}$ & $\begin{array}{c}\text { No. of } \\
\text { experiments }\end{array}$ & $\begin{array}{c}\text { Total no. } \\
\text { of eggs } \\
\text { inseminated }\end{array}$ & $\begin{array}{c}\text { No. (\%) of eggs } \\
\text { penetrated by } \\
\text { spermatozoa* }\end{array}$ \\
\hline CCM & $5 \% \mathrm{CO}_{2}$ in air & 3 & 30 & $11(36.7)$ \\
& Pure air & 3 & 26 & $15(57.7)$ \\
mT & $5 \% \mathrm{CO}_{2}$ in air & 5 & 34 & $17(50.0)$ \\
& Pure air & 3 & 25 & $11(44.0)$ \\
BWW & $5 \% \mathrm{CO}_{2}$ in air & 2 & 14 & $4(28.6)$ \\
& Pure air & 2 & 7 & $3(42.9)$ \\
\hline
\end{tabular}

* Spermatozoa were preincubated for $2 \mathrm{~h}$ in $\mathrm{Ca}^{2+}$-free medium before mixing with eggs in the presence of $\mathrm{Ca}^{2+}(1.7 \mathrm{mM}$ for $\mathrm{CCM}$ and $\mathrm{BWW}, 2.0 \mathrm{mM}$ for $\mathrm{mT})$. Eggs were examined $2 \mathrm{~h}$ after insemination.

\section{PLATE 1}

Figs 1 and 2. Phase-contrast micrographs of dolphin spermatozoa, surface view (Fig. 1) and side view (Fig. 2). $\times 1200$.

Fig. 3. Scanning electron micrograph of spermatozoa. A, acrosomal region; Pa, post-acrosomal region, showing parallel longitudinal ridges. $\times 11000$.

\section{PLATE 2}

Figs 4 and 5. Sagittal (Fig. 4) and parasagittal (Fig. 5) sections of a spermatozoon. A, acrosomal region; E?, probable equatorial segment of the acrosome, which is distinct only in the sagittal section; $\mathrm{N}$, nucleus; $\mathrm{Pa}$, post-acrosomal region. $\times 43000$.

\section{PLATE 3}

Fig. 6. Transverse section through the post-acrosomal region of a spermatozoon. Thirteen ridges are clearly visible. The fourteenth and fifteenth ridges may be united. If the ridges are evenly distributed on the sperm surface, 16 ridges may be present. $\times 39000$.

Figs 7 and 8. Post-acrosomal region seen under higher magnifications. N, nucleus; Ne, nuclear envelope; Pad, post-acrosomal dense laminae; Pm, plasma membrane. Fig. 7, $\times 60000$; Fig. 8, $\times 94000$.

Fig. 9. Longitudinal section of a spermatozoon through the middle piece. Note the presence of two different types of mitochondria, type a staining lightly in comparison to those of type $b$. $\times 28000$.

\section{PLATE 4}

Figs 10 and 11. Longitudinal (Fig. 10) and transverse (Fig. 11) sections through the middle piece. The line on Fig. 10 indicates the plane of the transverse section of Fig. 11. Fig. 10, $\times 18000$; Fig. 11, $\times 38000$.

Figs 12-14. Phase-contrast micrographs of zona-free hamster eggs penetrated by dolphin spermatozoa. Fig. 12. One swollen sperm head (s) and three unpenetrated spermatozoa (u) are visible. Figs 13 and 14. A swollen sperm head (s) photographed at two different focal planes. The tail accompanied by the swollen sperm head is clearly visible in Fig. 14. Fig. 12, $\times 450$; Figs 13 and $14, \times 1000$. 
PLATE 1
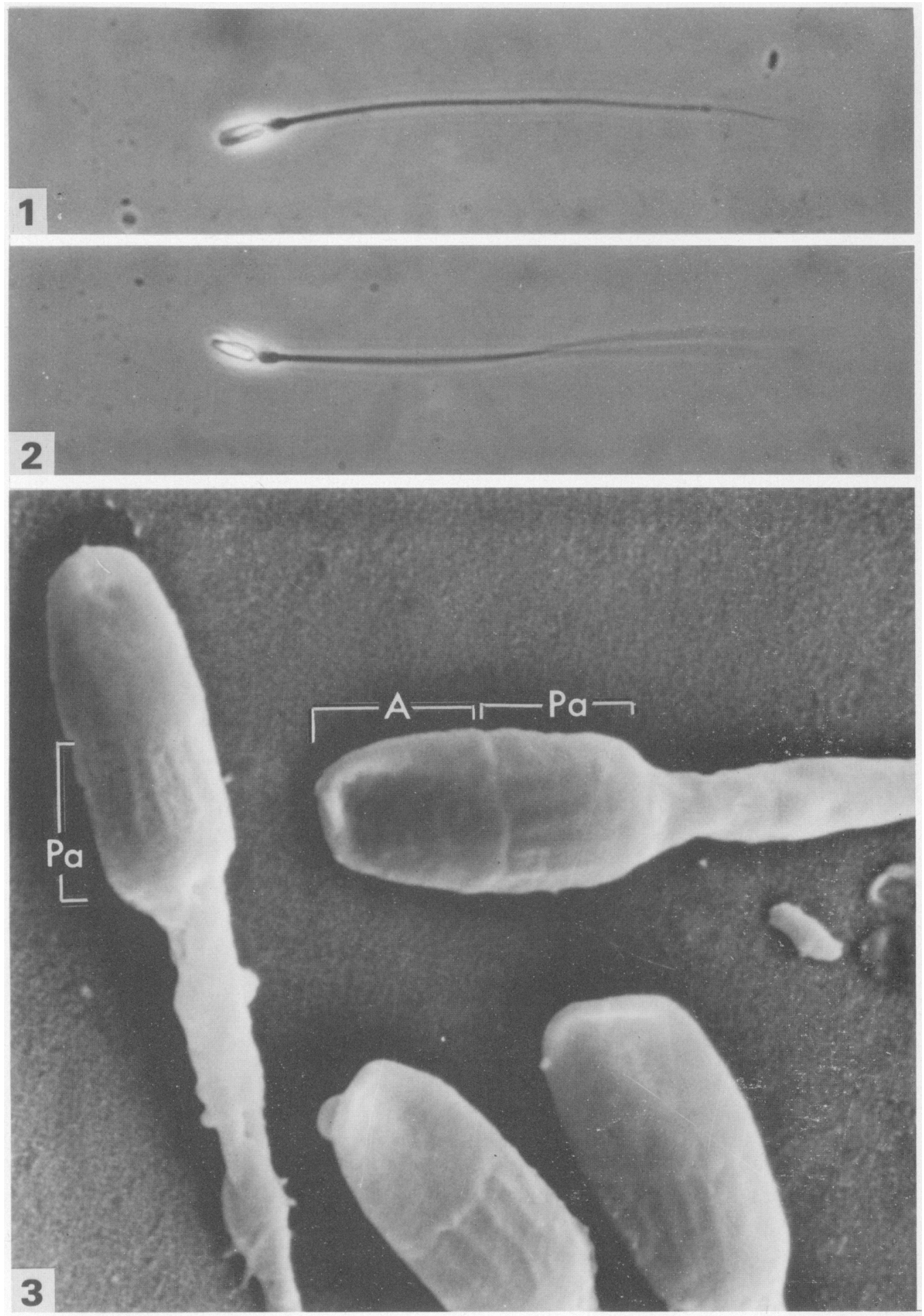

( Facing $p .512$ ) 
PLATE 2

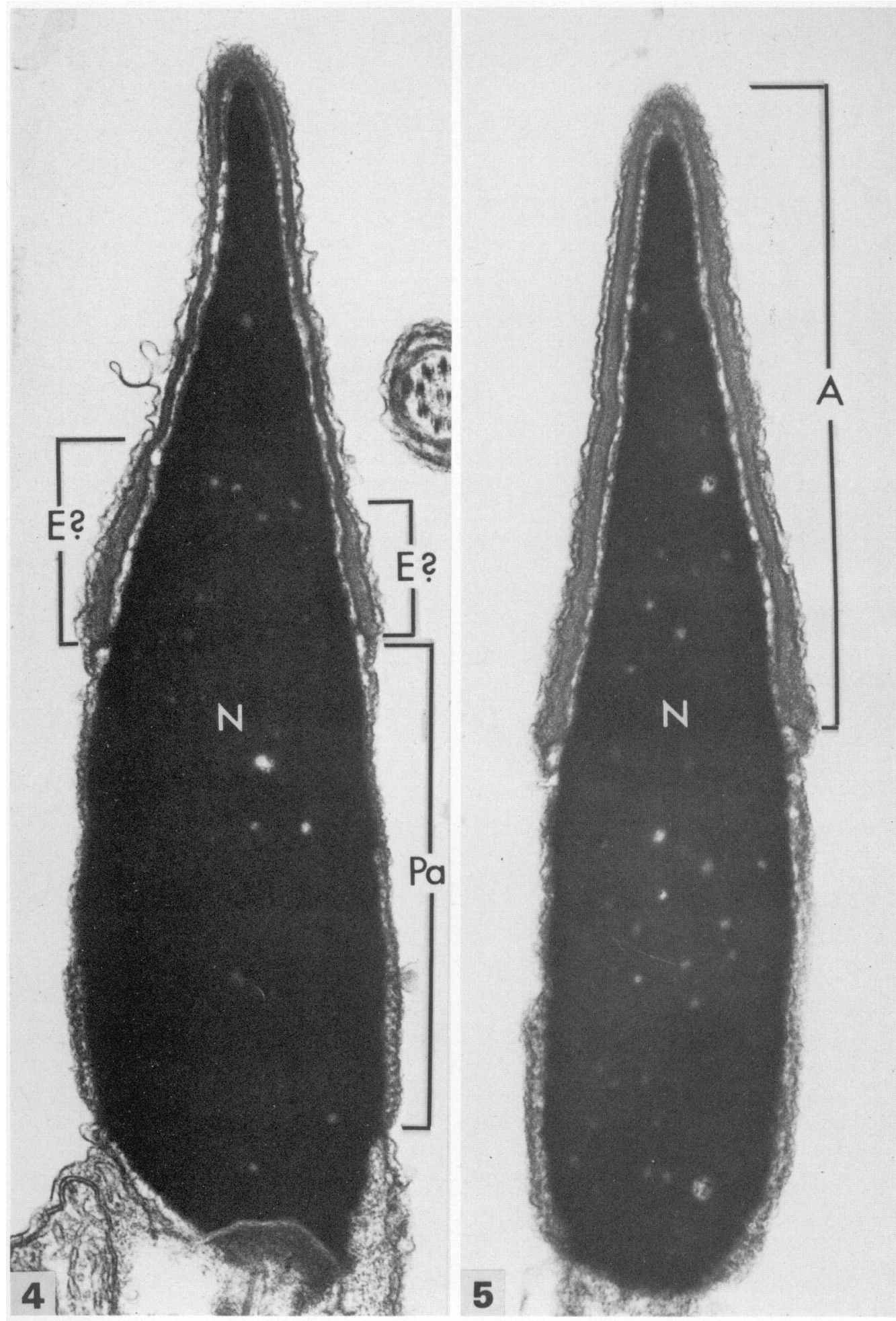


PLATE 3
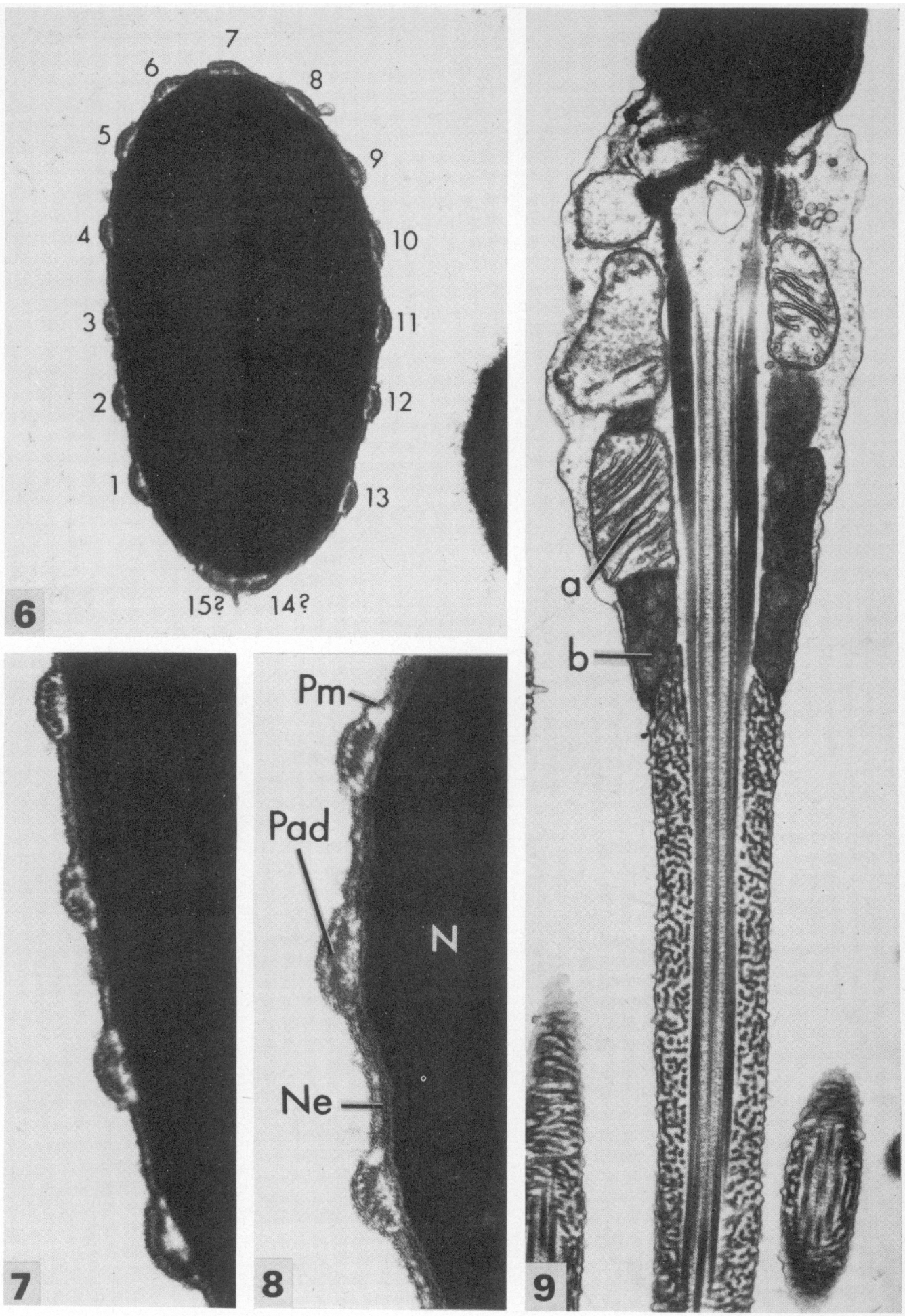
PLATE 4
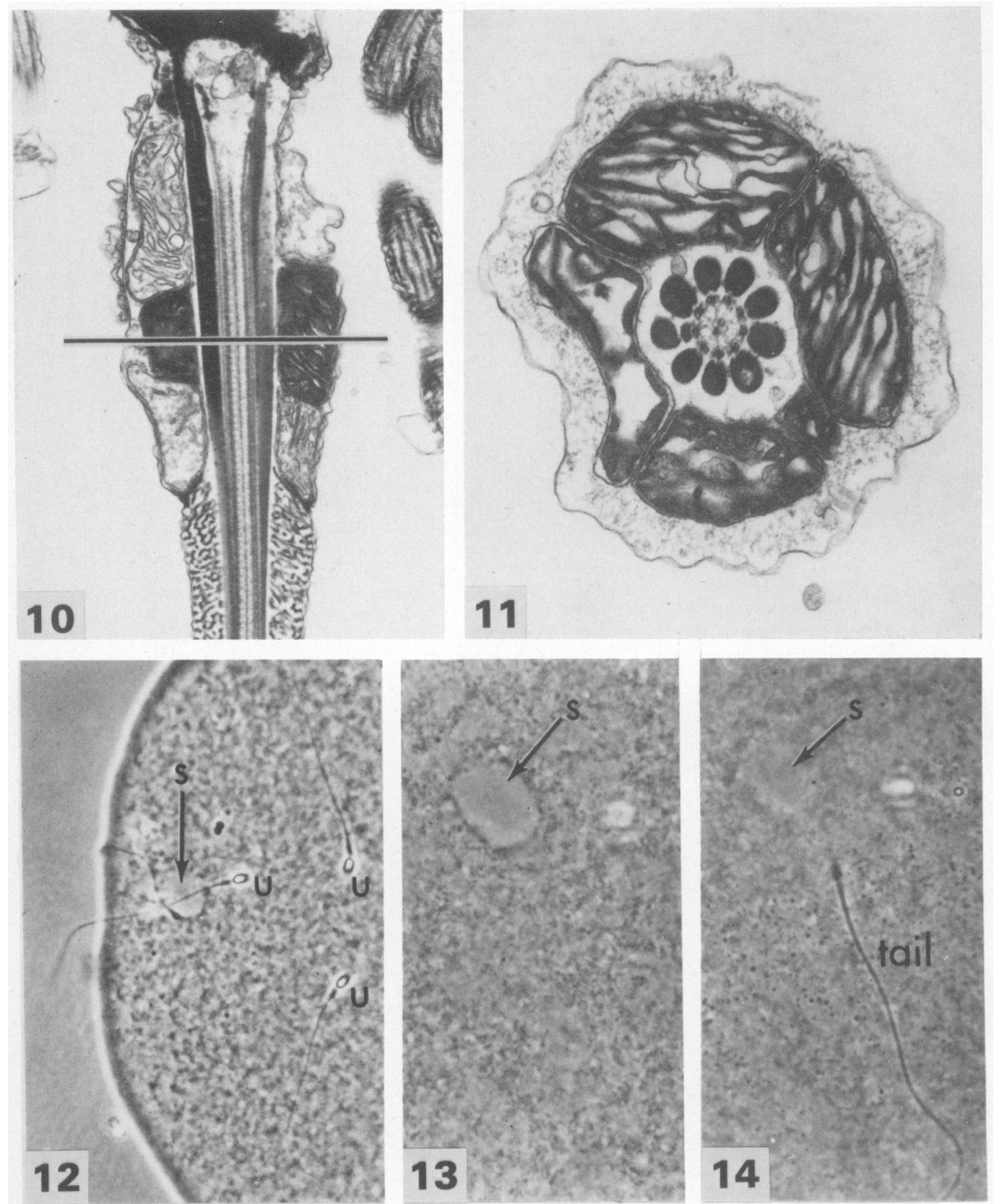


\section{Discussion}

The present study has demonstrated that dolphin spermatozoa can survive well and retain their fertilizing capacity after freezing and thawing, although the maximum period of storage in this study was only 10 days.

The general morphology of the dolphin spermatozoon is similar to that of the sperm whale (Matano et al., 1976): they are characterized by a large post-acrosomal region which occupies almost one-half of the sperm head. SEM micrographs of the sperm whale spermatozoa did not reveal any novel surface structures in the post-acrosomal region (Matano et al., 1976), but dolphin spermatozoa clearly showed very distinct ridges running parallel to the long axis of the head Pl. 2, Fig. 3). It is possible that these ridges participate in the membrane fusion of the spermatozoon with the egg and/or in the early post-fusion events. The ridges obviously do not prohibit cross-species egg penetration. The functional significance of the two types of middle piece mitochondria with different affinities for heavy metal stains is not known.

Spermatozoa of all eutherian mammals, as far as we are aware, must undergo capacitation and the acrosome reaction before they become capable of penetrating egg investments and fusing with the vitellus (Yanagimachi, 1977; Bedford \& Cooper, 1978). The present study was not specifically designed to demonstrate capacitation and the acrosome reaction of dolphin spermatozoa, but the acquisition by spermatozoa of the ability to fuse with the vitellus only after preincubation seems to indicate the need for capacitation and the acrosome reaction before fertilization in this species. Whiplash motility has been described for spermatozoa of some other mammalian species in association with their capacitation and/or acrosome reaction (Yanagimachi, 1970; Yanagimachi \& Usui, 1974; Fraser, 1977; Overstreet \& Cooper, 1979; Katz \& Yanagimachi, 1980).

A part of this study was supported by a grant from US-PHS (HD-03402). We thank Dr S. Seager, Department of Veterinary Physiology and Pharmacology, Texas A \& M University, Mr W. Gilmartin and the Naval Ocean Systems Center at Kaneohe, Hawaii, for generously supplying the dolphin semen samples; Dr J. M. Cummins for making valuable suggestions; and Mrs M. Ikeda for assisting in the preparation of the manuscript.

\section{References}

Bedford, J.M. \& Cooper, G.W. (1978) Membrane fusion events in the fertilization of vertebrate eggs. In Cell Surface Review, Vol. 5, Membrane Fusion, pp. 66-125. Eds G. Poste \& G. L. Nicolson. NorthHolland, Amsterdam.

Biggers, J.D., Whitten, W.K. \& Whittingham, D.G. (1971) The culture of mouse embryos in vitro. In Methods in Mammalian Embryology, pp. 86-116 (Table 6-5). Ed. J. C. Daniel. W. H. Freeman, San Francisco.

Fawcett, D.W. (1975) The mammalian spermatozoa. Devl Biol. 44, 394-436.

Fisher, H.D. \& Harrison, R.J. (1970) Reproduction in the common porpoise (Phocoena phocoena) of the North Atlantic. J. Zool., Lond. 161, 471-486.

Fleming, A.D. \& Yanagimachi, R. (1981) Effects of various lipids on the acrosome reaction and fertilizing capacity of guinea pig spermatozoa with special reference to the possible involvement of lysophospholipids in the acrosome reaction. Gamete Res. (in press).

Fleming, A.D., Yanagimachi, R. \& Yanagimachi, H.
(1979) Fertilizability of cryopreserved zona-free hamster ova. Gamete Res. 2, 357-366.

Fraser, L.R. (1977) Motility pattern in mouse spermatozoa before and after capacitation. J. exp. Zool. $212,439-444$.

Harrison, R.J. \& Brownell, R.L., Jr (1971) The gonads of the South American dolphins Inia geoffrensis, Pontoporia blainvillei and Sotalia fluviatilis. $J$. Mammal. 52, 413-419.

Harrison, R.J. \& Ridgway, S.H. (1971) Gonadal activity in some bottlenosed dolphins (Tursiops truncatus). $J$. Zool., Lond. 165, 355-366.

Harrison, R.J., Brownell, R.L., Jr \& Boice, R.C. (1972) Reproduction and gonadal appearances in some odontocetes. In Functional Anatomy of Marine Mammals, Vol. 1, pp. 361-429. Ed. R. J. Harrison. Academic Press, New York.

Imai, H., Niwa, K. \& Iritani, A. (1979) Time requirement for capacitation of boar spermatozoa assessed by their ability to penetrate the zona-free hamster egg. J. Reprod. Fert. 56, 489-492.

Kanwar, K.C., Yanagimachi, R. \& Lopata, A. (1979) 
Effects of human seminal plasma on the fertilizing capacity of human spermatozoa. Fert. Steril. 31, 321-327.

Katz, D.F. \& Yanagimachi, R. (1980) Movement characteristics of hamster spermatozoa within the oviduct. Biol. Reprod. 22, 759-764.

Mahi, C.A. \& Yanagimachi, R. (1978) Capacitation, acrosome reaction and egg penetration by canine spermatozoa in a simple defined medium. Gamete Res. 1, 101-109.

Matano, Y., Matsubayashi, K., Omichi, A. \& Ohtomo, K. (1976) Scanning electron microscopy of mammalian spermatozoa. Gunma Symposia Endocrinol. $13,27-48$.

Overstreet, J.W. \& Cooper, G.W. (1979) Effect of ovulation and sperm motility on the migration of rabbit spermatozoa to the site of fertilization. $J$. Reprod. Fert. 55, 53-59.

Seager, S.W.J., Platz, C.C. \& Fletcher, W.S. (1975) Conception rates and related data using frozen dog semen. J. Reprod. Fert. 45, 189-192.

Seager, S., Gilmartin, W., Moore, L., Platz, C. \& Kirby, V. (1981) Semen collection (electroejaculation), evaluation and freezing in the Atlantic bottlenosed dolphin (Tursiops truncatus). Proc. Am. Ass. Zoo Vet. (in press).

Yanagimachi, R. (1970) The movement of golden hamster spermatozoa before and after capacitation. J. Reprod. Fert. 23, 193-196.

Yanagimachi, R. (1972) Penetration of guinea-pig spermatozoa into hamster eggs in vitro. J. Reprod. Fert. 28, 477-480.

Yanagimachi, R. (1977) Specificity of sperm-egg interaction. In Immunobiology of Gametes, pp. 255-295. Eds M. Edidin \& M. H. Johnson. Cambridge University Press.

Yanagimachi, R. (1978) Calcium requirement for spermegg fusion in mammals. Biol. Reprod. 19, 949-958.

Yanagimachi, R. \& Usui, N. (1974) Calcium dependence of the acrosome reaction and activation of guinea pig spermatozoa. Expl Cell Res. 89, 161-174.

Yanagimachi, R., Yanagimachi, H. \& Rogers, B.J. (1976) The use of zona-free animal ova as a test-system for the assessment of the fertilizing capacity of human spermatozoa. Biol. Reprod. 15, 471-476. 